\title{
Mulheres e suas casas: reflexões etnográficas a partir do Brasil e da África do Sul*
}

\section{Antonádia Borges**}

\section{Resumo}

A partir de duas experiências etnográficas, uma no Brasil e outra na África do Sul, abordo neste artigo a relação imaginativa que as mulheres engendram com suas moradias, concebidas a partir de um ideário modernista de urbanismo. Com os investimentos teóricos e metodológicos dessas mulheres, o que era habitação se torna a casa, na medida em que elas mesmas engendram a habilidade de receber, de se tornarem anfitriãs. As cruciais lições aprendidas com essas mulheres, suas casas, seus métodos e teorias nos ajudam a desafiar cisões ainda perenes na antropologia como aquelas entre público $e$ privado e entre sujeito e objeto.

Palauras-chave: Gênero, Política, Moradia, Brasil, África do Sul.

\footnotetext{
" Recebido para publicação em 8 de junho de 2011, aceito em 3 de setembro de 2012.

** Professora do Departamento de Antropologia da Universidade de Brasília. antonadia@uol.com.br
}

cadernos pagu (40), janeiro-junho de 2013:197-227. 
Reflexões etnográficas a partir do Brasil e da África do Sul

Women and Their Houses: Ethnographic Thoughts on Brazil and South Africa

\begin{abstract}
The present article raises epistemological questions upon two different ethnographic experiences, in Brazil and in South Africa. Both research experiences are focused on women who develop along with their homes an imaginative relationship, challenging modernist perspectives on how to inhabit this world. Our main concern here is to animate further thoughts on how we as anthropologists could learn from our hosts' methods and theories.
\end{abstract}

Keywords: Gender, Housing Policies, Home, Brazil, South Africa. 
Um de meus interesses atuais de pesquisa são os processos de investigação de mulheres a respeito de suas casas no Brasil $e$ na África do Sul, mais especialmente no entorno do Distrito Federal brasileiro e na região noroeste de Kwazulu-Natal. Os dois universos, apesar do oceano de distância e história que os separam, podem ser facilmente aproximados se tomamos a ingerência do Estado na constituição do espaço, especialmente a que teve cabo ao largo da segunda metade do século $\mathrm{XX}$, na qual se mesclavam ideais modernistas e segregacionistas em ambos os países. Eu mesma principiei minhas reflexões com essa constatação visível a qualquer um que observe de fora as casas de uma cidade-satélite como o Recanto das Emas ou uma township como Madadeni, por exemplo. ${ }^{1}$ Em outras palavras, também compartilhei do interesse pelas políticas públicas de fora para dentro, isto é, pelas políticas de Estado e a constituição modernista das periferias urbanas.

Felizmente, graças à gentileza das pessoas que me receberam em campo e aos colegas acadêmicos que comigo partilharam seus problemas, pude avançar para além dessa homogeneização que afirma o caráter modernista de certa governamentalidade, ao mesmo tempo em que dá vida a uma periferia urbana que é idêntica, em qualquer parte do mundo. A possibilidade de conhecer os domínios internos das casas me foi proporcionada, especialmente, por mulheres que no interior de seus lares, que eu até então entendia como espaço preponderantemente constituído a partir do violento modernismo de Estado, investigam cotidianamente formas de solucionar os enigmas que a vida lhes apresenta, transformando o que era mera habitação em casa.

Se parte considerável de sua energia é despendida na tarefa de receber e, nesse processo, de constituírem a si mesmas como

\footnotetext{
1 Township é o nome dado aos conjuntos habitacionais segregados, forjados para abrigar a força de trabalho de não-brancos em zonas urbanas sul-africanas. Para o caso específico de Madadeni, ver a obra de Hart (2002).
} 
Reflexões etnográficas a partir do Brasil e da África do Sul

anfitriãs, como antropóloga fui amplamente beneficiada por tal expertise. Ao longo deste artigo procurarei esclarecer alguns dos motivos que me levaram, a partir de minha experiência específica de pesquisa, a chamá-las de anfitriãs - evitando tanto termos que considero derrogatórios como nativo ou objeto quanto outros, como interlocutor ou sujeito, que, tanto quanto o que aqui proponho, almejam uma simetria entre essas pessoas que se encontram, acadêmicos ou não, cada qual em suas investigações (Borges, 2009b).

Em meu trabalho de pesquisa etnográfica mais recente, tenho percebido - também em contraste com meus investimentos analíticos anteriores - que os domínios internos das moradias e os seus entornos desafiam nossas análises na medida em que tratam de dimensões da realidade que práticas de campo convencionais nem sempre permitem acompanhar. Resulta dessa constatação uma dúvida bastante salutar sobre os conceitos e enquadramentos teóricos e metodológicos com que habitualmente tinha trabalhado $e$, consequentemente, uma abertura para a ideia de pesquisar as pesquisas alheias como forma de criticamente dar-me conta da presença inerente de tal descompasso - entre marco conceitual e experiência de pesquisa - em nosso ofício.

A proposta de investigar os processos de investigação alheios não é em absoluto uma novidade; ao menos desde Garfinkel (1967) até os estudos contemporâneos sobre agência e reflexividade, muitos já tiveram pretensões similares. Como há tempos o sublinham Law e Hassard (1999), diante das limitações de nosso vocabulário, a sociologia dos próprios atores não pode ser silenciada em nome de mantermos viva a crença de que temos de antemão o arsenal analítico capaz de lidar com o imprevisível intrínseco a qualquer investigação. Como não se trata de uma guerra - por sorte, uma a menos! - estamos eximidos de usar armas. E, como tampouco é uma oficina mecânica, podemos deixar as ferramentas de lado e nos lançarmos a fazer pesquisa junto com as pessoas que nos recebem em suas vidas que em si se tratam de um contínuo processo de pesquisa, do qual 
participamos de modo superficial e circunscrito, no tempo e no espaço, como visitas passageiras.

Antes de esclarecer a relação entre minha forma de pensar o fazer antropológico e um interesse por uma antropologia das mulheres e de suas casas, convido a leitora e o leitor para um breve passo atrás. Iniciarei meu argumento com um preâmbulo que recupera parte de minha trajetória como pesquisadora, em que indico alterações substantivas em meu modo de pensar, amplamente apoiado pelas investigações particulares de meus anfitriões em cada momento distinto. Por meio de concisas alusões a pesquisas anteriores, pretendo iluminar alguns aspectos $e$ eventos que contribuem para o problema central de minha proposta atual de investigação, o que intrinsecamente me levará a abandonar diversos elos importantes, que talvez tornassem a exposição mais densa. Por meio de um desenho de traços fortes e sucintos que esboçam apenas uma silhueta, espero despertar a leitora e o leitor para outros e futuros diálogos.

\section{Antecedentes}

$\mathrm{Na}$ gênese das reflexões que ora apresento encontram-se duas pesquisas anteriores, cuja forma e conteúdo esclarecem muitos dos desdobramentos posteriores e, consequentemente, do estado atual de minha investigação. Dessas investigações de maior fôlego que estão no vértice desta pesquisa sobre mulheres e suas casas, destaco primeiramente uma, realizada no estado do Paraná, entre atingidos por barragem, no final dos anos 1990. A vida daquelas pessoas, assim como de muitas de minhas anfitriãs atuais, estava marcada por contínuos processos de intervenção estatal em seus cotidianos, por ações que culminaram com seus desenraizamentos, seus despejos $e$, por fim, com seu reassentamento em um lugar inóspito, esquadrinhado qual a lógica modernista de governo que as tratava como marionetes burlescas no teatro do desenvolvimentismo. Naquela ocasião, em minha análise, a casa e seu entorno figuraram como simples 
Reflexões etnográficas a partir do Brasil e da África do Sul

objetos presentes nos discursos e nas diversas performances públicas levadas a cabo por grupos políticos que, em meio à própria disputa, se constituíam como rivais ou aliados (Borges, 1999; Borges, 2010a).

A outra pesquisa teve lugar no Distrito Federal brasileiro, junto com moradores da "cidade-satélite" Recanto das Emas. ${ }^{2}$ Nesta última ocasião, meu diálogo se deu primordialmente com pessoas que se tornaram beneficiárias do governo local, "ganhando"3 um lote depois de muito terem lidado com a burocracia estatal, sempre a partir da obrigação de comprovarem seu "Tempo de Brasília". O Tempo de Brasília era condição sine qua non para qualquer um que pretendesse se envolver com o governo em um processo de demanda por um lote. A concepção local a respeito do tempo de vida em Brasília como demarcador de uma transformação dos sujeitos ancorava-se no princípio do sacrifício, na medida em que migrantes, entendidos como sem raízes, após cinco anos morando sabe-se lá em que circunstâncias no Distrito Federal, deveriam demonstrar aos olhos de todos, mas especialmente aos do governo local, terem se tornado aptos $e$ legítimos demandantes por direitos, especialmente à moradia. Naquele momento, interessei-me pelas relações de engajamento com a busca de um lugar para morar como produção de laços políticos entre as pessoas, e entre essas e certos objetos ofertados pelo governo. Gradualmente, começava a me despertar para uma associação entre pessoas e suas moradas que identificava na

2 O Distrito Federal brasileiro não é dividido em cidades, mas, desde sua última constituição em "regiões administrativas". Embora o Plano Piloto seja uma região administrativa como todas as demais, são chamadas de "cidades-satélites" as regiões administrativas que "gravitam" ao seu redor. Nessa perspectiva quem não mora no Plano Piloto é reduzido à condição de servidor de quem vive no "centro do poder".

3 Utilizo aspas porque o "ganhar" aqui não se refere a um presente isento de interesse, a um dom absoluto. Em todos os casos, as famílias beneficiárias acabam de diversas maneiras pagando de forma pecuniária pelo bem que lhes é entregue pelo governo (Borges, 2004a). 
própria casa um terceiro ${ }^{4}$ crucial em todo o processo de constituição cotidiana do Estado e de participação política de pessoas que lutam por um lugar para morar (Borges, 2004a).

A reflexão que tenho proposto desde então se encarrilha em um debate a respeito da pertinência ou não de privilegiarmos teorias políticas sobre o Estado que desprezam formas políticas outras - mesmo contemporâneas - que não sejam tributárias da "hierarquia global de valores". ${ }^{5}$ Para efeitos de contextualização, mencionarei duas saídas frontalmente concorrentes em jogo na antropologia atual. Por um lado, temos certa literatura antropológica que lida com a política e a presença do Estado na vida cotidiana. Esta considera as margens do Estado junto às suas partes centrais como um corpo único e inteiro (Das, 2006; Das \& Poole, 2004). De acordo com essa perspectiva, onde quer que haja Estado, este sempre estará "tocando" as pessoas por meio dos objetos que as circundam (especialmente suas casas). A imanência do Estado seria, nessa leitura, a forma de sua própria existência. Outra perspectiva afirma que o Estado existe de maneira autônoma, transcendente. Segundo tal proposta analítica, embora os indivíduos e suas comunidades estejam sempre seguindo os movimentos e as ordens do Estado, sua relação não é de contato (e de provável transformação mútua), mas de mímica, de imitação unidirecional. Lançando mão de figuras de linguagem como sombras ou fantasmas, esta última abordagem entende a relação entre o Estado e as pessoas como um simulacro, cuja magia - para continuarmos com termos frazerianos - se transmitiria não pelo contato, mas pela necessidade de se assemelhar (Ferguson, 2006).

\footnotetext{
4 A noção de terceiro encontra inspiração nos escritos de Charles Peirce, para quem o entendimento resulta de uma relação entre distintas consciências a propósito de um objeto ou terceiro (Peirce, 1878).

${ }^{5}$ Embora utilize aqui o termo cunhado por Herzfeld (2003), abordagens e conclusões similares a dele podem ser encontradas também em Ferguson $(1994 ; 2006)$ ou Scott (2009).
} 
Reflexões etnográficas a partir do Brasil e da África do Sul

Ambos os posicionamentos ensejaram debates diversos: de posicionamentos laudatórios a refutações críticas. A meu ver, os limites heurísticos desses modelos se devem, sobretudo, ao fato de estarem focados especialmente sobre eventos e performances públicas. A fim de entender a presença do Estado na vida cotidiana como agência criada e ao mesmo tempo criadora do inusitado, do imprevisto, em suma, do não necessariamente reativo ao Estado, defendo a necessidade de outra perspectiva teórica.

Acredito que se quisermos avançar para além de uma suposta homologia entre as formas de morar e as formas de ação e reflexão políticas, é imperativo entender e comparar os diversos sentidos da casa, seja como ordem moral e cosmológica, como abrigo, como forma de ocupação e transformação. Esse entendimento, translúcido para as pessoas com as quais fazemos pesquisa, constitui para nós mesmos uma tarefa bastante trabalhosa, na medida em que seguimos presos nas celas dualistas que nos fazem aderir quase que irrefletidamente aos jogos de oposições como aqueles imortalizados por Pierre Bourdieu desde a Casa Cabília (1972). ${ }^{6}$

Voltando às experiências de investigação anteriormente mencionadas, destaco brevemente alguns ensinamentos que nasceram do próprio processo de pesquisa e do gradual entendimento da casa como "actante" em associação com pessoas comuns e pessoas com mandatos institucionais - sejam membros do governo ou de outra instituição. ${ }^{7}$ Em ambos os contextos,

6 Faço uma ressalva quanto à diferença entre a casa em La Maison Kabyle e a casa em Célibat et condition paysanne (1962). Bourdieu (2002) e muitos outros (por exemplo, Woortman, 2004 ou Jenkis, 2010) corroboram sua constatação de que para a pesquisa feita na França ele se aproxima teoricamente da noção de casa tornada corrente a partir dos esforços de sistematização de dados etnológicos empreendidos por Claude Lévi-Strauss. Nessa última chave, a casa ou maison é entendida como uma pessoa moral que se estende no tempo e no espaço, que se entrevê não somente em sua forma material e lógica, mas, igualmente, em suas nuances não-materiais e cosmológicas (Lévi-Strauss, 1983).

7 Embora bastante difundida, recupero a definição de Latour, para quem: "a palavra actante, colhida na semiótica, permite estender a questão social a todos 
aprendemos a desconfiar das teorias correntes sobre a chamada "política dos pobres" que, invariavelmente, apostava em categorias de acusação, como clientelismo e alienação política, para se referirem à dita "inércia de populações" que, de acordo com essa visão exterior e estigmatizante, ficavam à mercê das políticas estatais, sem qualquer agência própria ou poder de transformação. ${ }^{8}$ As partes em relação, beneficiários-eleitores $e$ funcionários-empregados na política, constantemente inventam formas de se combinarem, de se colocarem em relação de inteligibilidade e importância (Boltanski \& Thévenot, 1991). Essa constatação me leva hoje a crer que, de fato, parte significativa de um projeto como o que empreendo atualmente tem a ver com a possibilidade de inventar um método de pesquisa e de diálogo com meus anfitriões e anfitriãs (em campo e na academia) que se dá na exata medida em que o processo de investigação avança $e$ a não mais assumir que existem métodos e técnicas prontas, capazes de serem tão somente "aplicados" em qualquer contexto, como se aqueles e aquelas que nos recebem em suas vidas fossem meros informantes, como se a literatura e os quadros conceituais fossem nada mais que ferramentas, sem considerar ambos como sujeitos de intervenção ativa, criativa e transformadora em nossos trabalhos. Em suma, estou convencida de que a pesquisa etnográfica é uma base segura para a construção de formulações teóricas desafiadoras frente aos limites que encontramos em teorias sobre as ações políticas em ambientes definidos a priori como periféricos e segregados. Mesmo a literatura antropológica que recusa os princípios evolucionistas, utilitários e desenvolvimentistas, quando permanecendo à margem da vida cotidiana das pessoas que nos recebem em nossos trabalhos de campo, acaba por construir edifícios teóricos marcados pelo modelo da reprodução, e não da agência criativa $e$

os seres que interagem em uma associação e que intercambiam suas propriedades." (2007:51).

8 A este respeito, ver a crítica elaborada por Semán (2009). 
Reflexões etnográficas a partir do Brasil e da África do Sul

transformadora (Borges, 2009a; 2009c). ${ }^{9}$ Cremos que essa tendência não se relacione apenas aos pressupostos característicos de uma sociologia da conservação (Borges, 2004b). Em nosso entendimento, a saída mais eficaz para a produção de teoria em antropologia é o engajamento visceral e contínuo com o trabalho de campo, a fim de que não nos "autonomizemos" da dúvida etnográfica. ${ }^{10}$

Ao longo desses últimos anos, por causa do caráter das sucessivas pesquisas em que me envolvi, passei a me interessar pelas saídas encontradas por pessoas que se veem capturadas pela máquina estatal no interior de suas casas e que dali são removidas, deslocadas, segregadas, em nome de um projeto político e de governo chamado muito precisamente pela literatura de modernista (Holston, 1993; Ferguson, 1994). A partir da investigação de minhas anfitriãs e anfitriões no Paraná ou no Distrito Federal, fui conhecendo múltiplas maneiras de lidar com a presença do Estado na vida cotidiana e o constante enigma de suas múltiplas encarnações - burocrática, política, eleitoral, democrática, desenvolvimentista, policialesca, autoritária, governamental etc. - que ora se apresentam como inextricavelmente sobrepostas ora como nitidamente autônomas e separadas. Dentre as variadas associações possíveis, meu interesse se voltou gradativamente para contextos de forte intervenção estatal sobre os espaço e tempo cotidianos das mulheres.

9 Conforme a coleção de artigos reunidos em Carsten \& Hugh-Jones (1995).

${ }^{10}$ Meu argumento encontra amparo e ressonância em propostas diversas que vão das linhas programáticas da etnometodologia, que mencionei no início deste artigo, a elaborações mais recentes acerca do valor heurístico da etnografia. Para duas contribuições distintas que caminham em direção similar a que aqui defendo ver o artigo de Nader (2011), em que a autora afirma que etnografia é uma teoria, uma teoria da descrição (p. 211) e Peirano (2012), para quem a boa etnografia não pode ser reduzida a um método, tendo em vista seu caráter intrínseco de "contribuição teórica". 


\section{Mulheres}

A proposta analítica que aqui desenvolvo nasce de uma aproximação das mulheres do Brasil e da África do Sul, dedicadas a garantir a posse, a propriedade, o direito de manter suas casas diante de constantes ameaças de expulsão, de despejo e, não raras vezes, de concomitante obliteração de sua presença da cena pública. Até o presente momento tenho investigado a agência de mulheres envolvidas em redes de ação coletivas diversas, algumas com caráter partidário, outras não governamentais, outras ainda de matiz religioso, dando ênfase aos minuciosos estudos que essas mulheres realizam a propósito da burocracia estatal e seu mandato de remoções (Borges, 2009a; Borges, 2009c).

Diferentemente das abordagens que qualificam esse tipo de ação como reações a situações de dominação, as tomo como formas de construção de conhecimento, as quais, ao longo do tempo, implicam mudanças na linguagem considerada legítima para definir a realidade social, provocando consequentemente alterações em nossa compreensão desse mesmo mundo $e$ convocando-nos a transformar nosso leque conceitual $e$ metodológico. O deslocamento epistemológico que proponho rechaça, portanto, uma realidade de dominação perene contra a qual as mulheres estariam meramente reagindo ao longo do tempo. As ações das mulheres que pesquisamos, entendidas como produções intelectuais ao largo da história, produziram transformações no mundo social e na própria ideia acerca de quem são essas mulheres e o que significa a (des)igualdade de gênero nesses contextos (Haraway, 1988).

A postura analítica que adoto advém, em suma, de uma tensão presente tanto nos estudos de gênero como nos constructos que emergem de minha própria pesquisa em face daquelas de minhas anfitriãs. As experiências prévias de investigação no Brasil e na África do Sul me asseguram que, por um lado, para além das diferenças históricas abissais, nos dois casos temos ideologias dominantes que têm sustentado a existência de uma 
Reflexões etnográficas a partir do Brasil e da África do Sul

complementaridade de papéis na qual às mulheres é assegurado o espaço doméstico e aos homens adultos o espaço público, também nomeado como político. Por outro lado, é notável que este ideário persista a despeito de investigações contemporâneas cujas contribuições têm ajudado a desbancar o senso comum dominante, fazendo emergir questões acerca dos limites explicativos de modelos analíticos de orientação estruturalfuncionalista, cujos eixos centrais tão somente traduzem certo atávico imobilismo social em cisões supostamente universais como natureza e cultura, doméstico e político etc. ${ }^{11}$

Para as lutas por independência e desenvolvimento desses países foi fundamental que especialmente as ações estatais estivessem sustentadas pelo conhecimento científico moderno $e$ pelo exercício da razão política esclarecida. Nesse processo de construção da legitimidade dos novos regimes, das novas democracias, foi reconhecida como verdadeira - no sentido de historicamente produzida e contemporaneamente aceita como um fato evidente - a relação desigual entre homens e mulheres. Entretanto, ainda que reconhecida, essa assimetria não alcançaria a importância de outras diferenças históricas herdadas do passado, a serem combatidas com mais urgência, como as derivadas de distinções discriminatórias de classe e raça. Embora a desigualdade de gênero tenha sido percebida como fruto da construção histórica de propriedades corporais e morais distintas para homens e mulheres, essa história raramente foi conectada com a dominação mais ampla (colonialista e racista), a qual, não se tinha dúvida, urgia combater. Houve inclusive momentos nos quais a assimétrica relação entre homens e mulheres passou a ser considerada evidência da particularidade cultural e, portanto, da independência de caráter de países que buscavam sua liberdade.

O patriarcalismo brasileiro foi muitas vezes nomeado como condição sine qua non para o tipo de construção republicana que

${ }^{11}$ Nesse debate, destaca-se a crítica proposta por Strathern (1988). 
se alcançou no país. ${ }^{12}$ Também na África do Sul, modelos hierárquicos patriarcais e gerontocráticos orientam algumas associações políticas de cariz patrimonialista (Oomen, 2005; Ntsebeza, 2006). A construção de uma socialidade em que as mulheres estivessem restritas ao espaço doméstico e gravitando ao redor de homens foi por vezes considerada uma forma de oposição e rechaço a um sistema de dominação que atingiria a todos de maneira mais uniforme, em suma, como resistência tanto aos governos coloniais quanto às missões cristãs. Nessa chave inseriu-se a ideia de que os direitos alcançados pelos homens se estenderiam às mulheres por meio dos laços de parentesco, fosse por consanguinidade ou por aliança. ${ }^{13}$

No entanto, dados bibliográficos mais contemporâneos sobre o Brasil e a África do Sul demonstram que a obliteração das mulheres da cena pública, longe de retratar uma realidade evidente, se trata bem mais de uma ação deliberada de ocultamento do passado, por meio de uma narrativa modernista que o torna inapelável, em uma manobra fundamental para a manutenção do status quo dominante, cujas propriedades costumam ser interpretadas não como resultantes de um tipo particular de conhecimento e formação histórica, mas como traços essenciais do caráter nacional (ou, em outras palavras, cultural) dessas sociedades (Aguiar, 2000; Hassim, 2006).

Mesmo que sempre tenha havido mobilização das mulheres e de outros sujeitos envolvidos em lutas pela igualdade de gênero,

\footnotetext{
12 Neuma Aguiar (2000) confronta as reflexões sobre a desigualdade de gênero nas obras de autores clássicos do pensamento social brasileiro que tratam mais diretamente do conceito de patrimonialismo (como Silvio Romero, Gilberto Freyre, Oliveira Vianna, Joaquim Nabuco e Sérgio Buarque de Holanda). Segundo a autora, "no âmbito das sociedades patrimoniais a intimidade entre público e privado não resultou em uma maior participação política ou econômica das mulheres nessa esfera pela própria origem patriarcal do estamento burocrático no contexto de um patrimonialismo patriarcal" (id.ib.:327).

${ }^{13}$ Para um apanhado analítico emblemático de tal diversidade de temas $e$ abordagens, ver a coletânea de estudos organizado por Gasa (2007).
} 
Reflexões etnográficas a partir do Brasil e da África do Sul

persiste uma recusa teórica (inclusive por parte de atores tidos como liberais) a abandonar os modelos patriarcais que azeitaram a porta de acesso ao mundo político contemporâneo nesses países. Em seu livro The Cry of Winnie Mandela, Ndebele (2003) sustenta que na África do Sul as conquistas da sociedade contemporânea na luta contra o apartheid foram e em larga medida seguem sendo pensadas, apresentadas e representadas como batalhas de grandes homens, ao passo que as mulheres, tal qual Penélopes, supostamente se mantiveram durante todo o tempo pacientes, em suas casas, "esperando".

Essa imagem de mulheres congeladas no tempo e no espaço, ao passo que os homens adultos lutavam pela independência, sustentou um inegável processo de transição à democracia, sem qualquer necessidade de afrontar os valores colados a esse tradicional poder de liderança masculino (Oomen, 2005). Nos notórios tribunais de verdade e reconciliação, o sofrimento das mulheres serviu inúmeras vezes para trazer à tona crimes perpetrados pelo regime racista contra seus parentes homens, em depoimentos pronunciados no domínio preponderantemente masculino da justiça transicional, considerado suficientemente legítimo para deliberar sobre o que fazer para reparar os danos e traumas vividos por mulheres vitimizadas (Cejas, 2007; Hassim, 2006; Ross, 2003; Krog et alii., 2009). Esses e outros estudos (como os de Das, 2006 ou de Debert \& Gregori, 2008) buscam ressaltar e desafiar modelos analíticos acadêmicos que se tornaram paradigmáticos. Procuram refutar perspectivas reducionistas que vinculam ou restringem a capacidade de tomada de decisão por parte das mulheres à sua identificação como alvo de violência tanto perpetrada quanto punida por homens adultos, detentores do poder de fazer justiça, literalmente com suas próprias mãos. Tendo em vista esse amplo quadro, me parece plausível afirmar que, nos cenários por mim estudados, a vulnerabilidade feminina encontra-se fortemente vinculada às já mencionadas (i) formas de exercício de poder (estatal, público e doméstico) e (ii) relações que essas pessoas 
logram manter com a casa e a terra que ocupam, das quais tratarei nas páginas que se seguem.

No Brasil e na África do Sul, no que tange ao direito à terra $e$ à moradia, especialmente em meios economicamente vulneráveis e culturalmente não hegemônicos, a chance concreta de as mulheres negociarem as formas de ocupação do espaço geográfico e social são exíguas. Mesmo que suas demandas sejam por vezes orquestradas sob as bandeiras de algum movimento social, sua legitimidade é constantemente questionada diante dos limites conceituais dados por formas políticas e jurídicas que privilegiam em suas políticas públicas sujeitos cujas identidades estão perpassadas por eixos considerados mais contundentes e, portanto, generalizáveis (como raça, etnia e classe ou, em outros registros, pobreza). Dado o caráter amplo do problema, em diálogo com a produção acadêmica sobre temas correlatos, voltamos nossa atenção para um universo muito específico de observação $e$ análise: as remoções e despejos perpetrados por autoridades estatais e que se dirigem preponderantemente às mulheres.

No Brasil, nosso trabalho tem como terreno uma cidade satélite próxima de Brasília onde o governo local mantém com as mulheres uma relação privilegiada. Ao mesmo tempo em que são as mulheres $\mathrm{o}$ alvo primordial das batidas policiais $e$ das derrubadas de barracos construídos nas áreas chamadas de "invasões", são elas também as que abarrotam as listas de espera por um beneficio estatal $e$ as caravanas de apoio eleitoral aos políticos locais com o objetivo de serem contempladas na distribuição de lotes urbanos orquestrada pelo governo local há décadas. A essa performance pública agrega-se um cotidiano marcado por um processo contínuo de investigação a propósito de problemas diversos que, a meu ver, relacionam-se com a suposta separação entre público e privado como domínios respectivamente masculino e feminino. As mulheres das quais estou próxima não apenas têm uma presença pública bastante ativa, especialmente por via da militância político-partidária e/ou seu trabalho em igrejas e associações comunitárias, como ainda, 
Reflexões etnográficas a partir do Brasil e da África do Sul

em suas casas, assumem a difícil tarefa de equalizar questões de ordem diversas que vão desde relacionamentos afetivos ao abastecimento de suas panelas. Se anteriormente eu percebia o quão fundamental era seu desemprego formal $e$ sua disponibilidade para ofertar ao governo local sua mais-valia política, é apenas neste momento que me dou conta do emaranhado de laços a que essas mulheres precisam se dedicar no interior de suas casas para que sua presença pública se torne possível (Borges, 2005).

$\mathrm{Na}$ África do Sul, tendo em vista que nunca antes ou durante o apartheid lhes foi garantida a propriedade legal de seus lares, as mulheres com quem faço pesquisa tornam-se presas fáceis de remoções e despejos, perpetrados pelos proprietários das terras em que seus parentes homens adultos costumavam trabalhar (Posel, 2006). Expulsas de suas casas, elas passam a ocupar uma posição ainda mais subalterna, dependente da atenção estatal - tanto em termos jurídicos, quanto assistenciais. A separação das mulheres dos homens (seja na "costumeira" etiqueta zulu, seja no envio de homens como migrantes das zonas rurais para as cidades a fim de trabalhar nas indústrias e minas antes e durante o apartheid) ainda hoje é considerada, mesmo por setores mais progressistas da intelectualidade sul-africana, um problema de menor importância, visto que não diretamente vinculado a questões de amplo escopo como o racismo ou a exploração laboral dirigida aos homens (Gasa, 2007).

$\mathrm{Na}$ etapa atual de minha pesquisa, além do envolvimento dessas mulheres com diversas lutas pelo direito a ter suas casas e suas terras, tenho tomado como objeto de análise os projetos levados a cabo no interior de suas moradias, os quais indicam uma abertura do próprio lar a vínculos que não são estritamente domésticos entre pessoas que não possuem uma casa para viver e aquelas que - já tendo garantido um teto sobre suas cabeças - compartilham sua expertise social a fim de fomentar aquilo que Fabian (1983) chamaria de coevalness entre pessoas que apesar de contemporâneas encontram-se ainda hoje apartadas no tempo e no espaço por conta 
da insegurança fundiária que castiga a maior parte da população. Além do trabalho etnográfico iniciado, encontro constantemente inspiração na ampla produção que tanto acadêmicos como mulheres militantes de ONGs produzem sobre esse tema na África do Sul contemporânea (Bähre, 2007; Ferguson, 2007). Esse quadro, somado à proximidade com certos grupos de mulheres, tem me permitido conhecer o pano de fundo diante do qual se desenrola o cotidiano de trabalho e luta política dessas mulheres.

\section{Casas}

A distribuição de lotes em assentamentos afastados - tanto no caso brasileiro das remoções de favela seguidas de construção de conjuntos habitacionais nas periferias, como nos casos de planejamento urbano de Brasília e da África do Sul - orienta-se por uma lógica de Estado que exige dos beneficiários o aprendizado da linguagem burocrática (Borges, 2004a; Borges, 2010b; Huchzermeyer, 2004). Minha pesquisa até recentemente tinha procurado analisar os sentidos com os quais se preenchem os formulários, os documentos exigidos dos beneficiários, os critérios de hierarquização nas filas de espera (as waiting lists da África do Sul), as alternativas encontradas por aqueles dispostos a burlar o sistema (as invasões, os door kickers etc.). ${ }^{14}$ Essa abordagem procurava entender como as pessoas lidam com o Estado por meio de suas casas e como o Estado lida com as pessoas por meio de suas casas. No entanto, com um olhar restrito

\footnotetext{
${ }^{14}$ Sophie Oldfield dedica-se a investigar conflitos próprios do pós-apartheid na África do Sul, marcados por embates entre pessoas outrora classificadas como Coloured, falantes de Afrikaans e pessoas negras, normalmente falantes de Xhosa. Vizinhos em zonas periféricas, providas de quase nenhuma infraestrutura, como o são os Cape Flats, por exemplo, colocam-se em disputa por um lugar para morar. Alguns, especialmente os mais jovens, que não estão inscritos em listas de espera produzidas desde o período do apartheid, diante da urgência de suas necessidades, se põem a invadir casas em construção ou abandonadas chutando suas portas (Oldfield \& Stokke, 2006 ) - sendo por isso são denominados door kickers.
} 
Reflexões etnográficas a partir do Brasil e da África do Sul

ao caráter habitacional da casa, tal perspectiva perdia de vista a transformação da moradia em casa e das pessoas que a ocupam em anfitriãs.

Com Dona Sibongile - ela aproveitando minha visita e eu aproveitando sua disposição - fomos à casa de Gloria. Gloria é uma mulher negra de aproximadamente 70 anos que, apenas nos anos 1970, quando o apartheid já tinha estraçalhado a África do Sul, foi removida do lugar onde morava, considerado um black spot, isto é, uma área ocupada por população negra em zonas destinadas exclusivamente para brancos. Dona Sibongile compartilha com sua amiga um passado comum, entretanto, ao contrario de Gloria, já não vive mais na township para onde ambas foram removidas. Graças à ajuda financeira recebida de seus filhos - especialmente de uma filha, que é juíza - ela mora hoje em uma confortável casa em um bairro outrora exclusivo de brancos. Nem Sibongile, nem Gloria, reclamam quando se trata de narrar o passado, embora repetir a mesma história lhes cause certo enfado, depois de passadas tantas décadas. Gloria quer falar de seu projeto atual e aproveita para nos levar até a escola de música que instalou na garagem de sua casa. Ambas eram professoras, porém Sibongile, aposentada, não ensina mais. Já sua amiga tem uma escolinha dentro de sua casa, para que os jovens aprendam a ler partituras, a conhecer gêneros musicais etc. Os comentários nostálgicos de Sibongile logo revelam que Gloria esteve exilada nos Estados Unidos e fez doutorado por lá. Sua amiga Gloria não deixa por menos e evoca também os logros de sua companheira. Se ela tem uma escolinha em sua casa, Sibongile tem um verdadeiro tribunal em sua confortável residência no centro da cidade, com todos os arquivos, muito bem organizados, de pessoas amigas que juntas formam um grupo de restitution claimants. ${ }^{15}$ Ambas constituem o mundo à sua volta

\footnotetext{
${ }^{15}$ Restitution claimants são pessoas que no pós-apartheid reivindicam as terras de que foram expulsas. Em específico as caracteriza o fato de terem tido propriedade privada das referidas áreas e de hoje disporem de documentos que
} 
com dificuldades, mas ainda assim sabem que os que nunca tiveram qualquer propriedade - que nada têm a reclamar do Estado -, e hoje vivem em barracos nas margens da township, podem muito menos que elas.

Bruna é uma jovem que mora no Recanto das Emas. Nasceu na Bahia e rodou o mundo até chegar à sua casa atual de onde terá que partir em breve, pois o lugar onde vive não pertence a ela ou à sua família, mas à igreja da qual seu pai é pastor. Se na casa de Gloria há uma escola, na de Sibongile um arquivo, na de Bruna há uma hospedaria por onde passam - e, às vezes ficam por vários dias - fiéis de vários lugares. No Distrito Federal brasileiro, a prática da invasão, seguida da construção de barracos, não ficou restrita a famílias interessadas em um teto. Também templos e igrejas foram construídos em áreas sem regularização fundiária, na maioria das vezes patrimônio público administrado pela Companhia Imobiliária de Brasília, a Terracap. Ao longo de décadas, inúmeras igrejas foram erguidas "na ilegalidade". Embora numerosas, visíveis e fundamentais no cotidiano das regiões administrativas do DF, sobre muitas igrejas que "invadiram" áreas públicas ou privadas, pesa a mesma pecha que incide sobre as famílias invasoras e seus barracos. Sucessivos governos tentaram lidar com o "problema". O mais recente, de Agnelo Queiroz, procura, desde 2011, encontrar um meio de cobrar das igrejas pelos lotes, a fim de regularizá-los. Interesses vários - do Ministério Público, passando pelos deputados distritais, grandes empreendedores imobiliários até as lideranças das diversas congregações - competem em um cabo de guerra sobre qual caminho tomar: se licitação, se doação etc. Em meio às disputas, os fiéis e os pastores de pouco renome - como Bruna e seu pai - ficam à mercê de uma decisão a respeito do templo/casa que os abriga.

o testifiquem. Sobre essa e outras modalidades de reivindicações por terra na África do Sul ver dentre outros Ntsebesa \& Hall (2007). 
Reflexões etnográficas a partir do Brasil e da África do Sul

Engana-se, porém, quem pensa - a despeito de todo o preconceito acerca do brotar "desenfreado" de igrejas na periferia do qual se toma conhecimento na imprensa local - que toda igreja tem seu templo. No Recanto das Emas, Laudicéia, pastora de uma igreja pentecostal, nunca conseguiu ocupar um lote e lá permanecer. Como saída, a pastora Laudicéia fez de sua casa um templo religioso: uma casa/templo. Na etnografia de Pinto (2011), vemos esta e outras pastoras, que não puderam ocupar um lote onde construiriam suas igrejas, estenderem suas casas para os "montes" - áreas de cerrado nas margens da cidade, no limite com os parques nacionais. Nesses lugares, ainda não totalmente esquadrinhados pelo projeto modernista, elas conduzem seus rituais, amparadas pelo sagrado das escrituras. Casa e templo se mesclam nessas duas experiências, ensinando-nos sobre o limite e a tensão que existem entre a vocação dos espaços públicos prevista pelo planejamento modernista da capital federal e sua efetiva ocupação. Para Bruna ou Laudicéia, as casas assim como os templos não são meras edificações, mas lugares para receber, para acolher, para dar abrigo. Na perspectiva dos governos, os lotes - para casas ou para templos - são essencialmente para dar, ou, como o sabemos, para vender (cf. nota 4). Ao passo que para quem neles habita, as casas são para receber.

Menciono essas quatro mulheres e suas casas a fim de deixar claro que nenhuma delas é um espaço doméstico como convencionalmente o pensamos. Gloria faz de sua "caixa de fósforos" para onde foi removida durante o apartheid uma escola de música, enquanto espera voltar para as terras de sua família de onde foi arrancada de forma violenta. ${ }^{16}$ Dos instrumentos dos

\footnotetext{
${ }^{16}$ As caixas de fósforo aludem ao caráter das casas construídas para confinar trabalhadores negros nessas áreas residenciais apartadas chamadas township. Sua forma e seu modo de ocupação em linhas retas diferem da casa redonda, com seu fogo central e suas zonas de circulação interna - para pessoas, objetos, luz, fumaça e sombra, como o são chamados os ancestrais - igualmente circular. Seguindo as reflexões de Ferguson (2006), não estou aqui opondo de forma
} 
jovens e crianças que ali se reúnem, por meio dos ensinamentos de Gloria, torna-se possível a emergência de uma arte insuspeitada. Sibongile, vivendo em uma casa de classe média, espaçosa, cede seus cômodos e seus dias para organizar documentos e petições de seus antigos vizinhos da township, como Gloria - todos restitution claimants. Dos arquivos $e$ memórias, Sibongile liberta traumas e esperanças que passam a habitar o seu lar.

Bruna, como milhares de pessoas em busca de um teto no Distrito Federal brasileiro, vive nos domínios físicos da Igreja na qual seu pai é pastor. Se lá permanecerem por ao menos cinco anos, poderão entrar nas listas de espera governamentais de distribuição de lotes urbanos. Porém, enquanto esperam, abrigam outras pessoas, outros sonhos e histórias, semeando este Tempo de Brasilia em direções insondáveis. Laudicéia por sua vez já passou por tal espera - seu Tempo de Brasilia lhe garantiu um lote e uma casa. Porém, como mulher, enfrentou inúmeras barreiras para realizar o desígnio de ser pastora, sendo a mais desafiadora o fato de não lhe ser concedido um espaço para sua igreja. Sem esmorecer diante das dificuldades, optou por abrir as portas de sua casa, transformando-a em um templo, onde o Espírito Santo visita a ela e a seus fiéis.

Em todos os casos mencionados, com matizes distintos, podemos perceber que as casas não se tratam de espaços privados, exclusivos, e consequentemente separados do espaço público - este, sim, "comum", tanto no sentido de pertencer a todos (ou quase todos), como de ser regido por regras mais ou menos compartilhadas que tornam o convívio entre estranhos viável. ${ }^{17}$ Muito lentamente comecei a me dar conta de que,

hierárquica a casa modernista à dita tradicional. Busco somente compreender as formas de ocupá-las e de torná-las vivas, encontradas por minhas anfitriãs.

${ }^{17}$ As reflexões sobre o Recanto das Emas beneficiam-se das pesquisas que ensejaram as dissertações de graduação de Fernandes (2009) e Pinto (2011). A preocupação com as casas é um tema que permeia também as teses de doutorado de Guimarães (2009), Vale (2009) e Ahlert (2011). 
Reflexões etnográficas a partir do Brasil e da África do Sul

embora os agentes e instituições estatais promovam ações a fim de controlar o espaço, no interior de um assentamento ou de um barraco emergem eventos inauditos que desafiam os aprisionamentos burocráticos e, portanto, sociológicos ou antropológicos desses fenômenos em termos de conexões causais estabelecidas a partir de dados e parâmetros que já trazemos em nosso arsenal interpretativo (Borges, 2004a; Hart, 2002).

Mulheres como Sibongile, Gloria, Bruna ou Laudicéia estão experimentando em suas casas formas de vida não "domésticas" no sentido ordinário do termo. E, mais, não são em absoluto uma exceção. Através do trabalho político cotidianamente levado a cabo sob o teto de suas casas, a hospitalidade forjada se revela fruto de um esforço político em favor de uma convivialidade que não obedece os limites e separações modernistas do tempo e do espaço.

As casas de nossas anfitriãs estão por ser conhecidas, tal como as pessoas que nelas habitam. O que é um enigma, um problema a resolver, não pode continuar a ser obliterado por nosso olhar distanciado, salvaguardado justamente por um dualismo modernista que divide o mundo entre público e privado e que, não só isso, sustenta ser de maior interesse para a ciência o que se passa no domínio suposto como público. A larga história modernista $-e$ as narrativas mestras da antropologia $e$ da sociologia se inscrevem nesse marco - na maioria das vezes tratou somente de atribuir significados à casa a partir de outros referentes. A casa remete à organização familiar, à organização política, à organização econômica, aos padrões de intervenção no espaço. Em suma, a casa em si não tem agência (Borges, 2009c). E, aqui, não se trata de voltar a um antropomorfismo, pelo contrário, cremos que o verdadeiro problema está em seguir afirmando apenas a dimensão humana de relações que envolvem também não humanos (Latour, 1999).

Nossa objeção dirige-se, portanto, ao isolamento da casa e a atribuição de valor à mesma a partir dos quadros analíticos do investigador, como se a casa não fosse o produto da ciência de quem com ela mora. De acordo com a perspectiva que critico, a 
casa não seria nada além de um índice de outro fenômeno, de maior generalidade e abrangência $e$, por essa mesma razão, considerado mais relevante. Tomando por base as pessoas que conheço nos dois campos de pesquisa e suas experiências, é bastante rentável, analiticamente, associar as mulheres às suas casas para compreendermos suas causas e, com essas causas em mãos, desafiar a separação estruturalista mais grosseira que divide o mundo social em esferas pública ou privada, em domínios masculino ou feminino, entre sujeitos e objetos.

Caso seguíssemos o raciocínio de Bruno Latour, segundo o qual a natureza nunca existiu como um domínio à parte, podemos pensar que talvez também o espaço doméstico, o privado, a casa, não se constituam apenas a partir de uma chave antropocêntrica. Afinal, quem vive na casa modernista, cartesiana, no reino da intimidade apartada do mundo lá fora? ${ }^{18}$ A quem estamos tentando convencer quando propomos uma forma de conhecimento que toma como parâmetro apenas a relação entre a casa e a socialidade modernista? Podemos continuar sustentando que nossa compreensão de outras casas e outras mulheres se paute por uma forma de habitar o mundo que é uma gota em um oceano de outros modos de viver? E, mais, podemos seguir assumindo que essa forma seja mais evoluída que as demais e, portanto, um inevitável objeto de desejo para qualquer pessoa dita "minimamente razoável"?

\section{Um convite para entrar}

Quando colocadas dentro dos marcos narrativos atuais as questões de gênero suscitam suspeita e descrédito por parte dos que as identificam como diretamente irmanadas a outras polêmicas tipicamente "modernistas". As lutas das mulheres com

\footnotetext{
${ }^{18}$ Mundo lá fora que seria a verdadeira res extensa, dotada de precedência e autonomia teleológicas em relação ao fluxo ordinário da vida na terra, de acordo com a crítica proposta por Stengers (2009).
} 
Reflexões etnográficas a partir do Brasil e da África do Sul

quem faço pesquisa, no Brasil e na África do Sul, no entanto ampliam as possibilidades teórica e política de pensar $e$ consequentemente de transformar as configurações sociais em que vivemos para além do modernismo. Nelas, o relativismo necessário ao respeito à diferença e o humanismo capaz de desafiar as formas tradicionais de opressão estão em permanente tensão. Em seus itinerários epistemológicos, minhas anfitriãs, envolvidas em ininterruptas sondagens, indicam um rechaço a uma ordem estruturalmente definida em termos imanentes $e$ duais, como o seriam o feminino e o masculino. A partir de suas investigações, passo a compreender que tais questões de gênero nos convocam a pensar em problemas que estão muito além daqueles demarcados pelo limite lógico e histórico do discurso modernista.

Os problemas de gênero não se restringem a optar por uma entre duas alternativas bem estabelecidas - como o público ou o privado, por exemplo. Não se trata tampouco de hierarquizar a experiência humana entre aquelas que realmente são importantes e valem a pena, e aquelas de menor valor, que não merecem sequer ser nomeadas, que podem por isso permanecer anônimas em um espaço obscuro e insondável que chamamos privado ou doméstico. Na medida em que propõem em seu presente passos que, menos do que efeitos de um passado, tratam-se de ensaios de um futuro desejável, distinto, que não poderia remeter a nada pré-existente, sob pena de fazer naufragar o próprio processo de mudança a que se dedicam, seus métodos de investigação têm muito a ensinar em termos epistemológicos à pesquisa em sociologia e em antropologia.

Se o problema de pesquisa aqui apresentado trata-se de uma questão etnográfica, ele exige sempre uma resposta ancorada na pesquisa antropológica tributária de um diálogo criativo com minhas anfitriãs. Pelo que tenho visto nos últimos anos, sinto-me à vontade para apostar na rentabilidade analítica de um estudo dos domínios internos às casas a partir dos itinerários e produção de conhecimento que têm em mulheres suas centrais protagonistas. Como procurei esboçar, a construção cotidiana de soluções para 
seus problemas nos oferece um exemplo de como romper com uma forma dual de pensar e intervir no mundo ao nosso redor. $\mathrm{O}$ acompanhamento etnográfico das composições que se estabelecem entre mulheres e suas casas pode nos oferecer elementos para transformar nossas próprias formas de investigar.

Meu entendimento atual, derivado dos embates e avanços alcançados por meio da investigação localizada e da comparação entre os dois contextos, aponta para a necessidade de entendermos a casa como constituída de espaços visíveis e de outros invisíveis à nossa percepção atual. Admitir o invisível, como o fazem, cada uma à sua maneira, as mulheres com quem pesquiso, significa antes de tudo, reconhecer que nossos conceitos e métodos sempre andam um passo atrás de nossas experiências. Como consequência dessa nova atitude, talvez tornemo-nos capazes de identificar na casa, no lar, um espaço teórico vivido sobre o qual se assentam tanto as análises políticas retrospectivas das pessoas com as quais fazemos pesquisa, quanto a cogitação de novos sentidos e inauditas formas de se viver.

Nesse processo encadeado de investigação sobre a política da moradia, tornou-se evidente que o conhecimento antropológico se desenvolve a partir de uma tríplice colaboração. Em meu entendimento atual, a teoria etnográfica põe em diálogo as teorias antropológicas acadêmicas, as teorias antropológicas de nossos anfitrióes $e$ as nossas próprias teorias, inextricavelmente associadas às duas primeiras. A teoria de meus anfitriões sobre o Tempo de Brasília me conduziu a perceber que em cidades como o Recanto das Emas, próximas de Brasília, as invasões, os barracos, os lotes e até mesmo o asfalto não eram meras moedas em uma troca eleitoral-clientelista, mas termos tão atuantes nas relações entre as pessoas quanto elas mesmas, dotados de história e agência - capazes de revelar associações entre as pessoas e suas casas que iam muito além das possibilidades elencadas nas fórmulas e conceitos regidos pelo Estado (Borges, 2004a).

O mesmo se deu na África do Sul. Nas retangulares "caixas de fósforo", como o são chamadas as casas de township para 
Reflexões etnográficas a partir do Brasil e da África do Sul

onde milhares de familias foram removidas ao largo de décadas, pude encontrar sinais de circularidade e, consequentemente, de circulação. Um objeto aqui, outro ali, e as conversas encetadas a propósito dos mesmos, conduziam a mim e a minhas anfitriãs para lugares e tempos que estavam muito além das quatro paredes que nos cercavam. Percebi que as casas, assim como as pessoas que nelas habitam, se estendiam, se replicavam, se multiplicavam. Povoadas por entes tangíveis - fossem humanas ou não - e por sujeitos aos meus olhos não visíveis, como o são os ancestrais, as casas se constituem na África do Sul não apenas como palco de controvérsias, como o indica a literatura mais voltada aos problemas de moradia (e.g. Harrison et alii, 2003). As casas são agentes dotados de qualidades que, junto às pessoas que nela vivem, e que por elas passam ocasionalmente, conformam uma composição inaudita, perceptível apenas quando dela nos aproximamos. Em suma, quando somos convidados a nelas adentrar.

\section{Referências bibliográficas}

AguiAR, Neuma. Patriarcado, sociedade e patrimonialismo. Sociedade e Estado 15(2), Brasília-DF, 2000, pp.303-330.

AHLERT, Martina. A cidade relicário: tempo, feitiços e festejos em Codó/MA. Projeto de doutorado, Antropologia, Universidade de Brasília, 2011.

AzEVEDO, Aina Guimarães. Três lugares para viver e um para morrer - o sentido das casas na África do Sul. Projeto de doutorado, Antropologia, Universidade de Brasília, 2009.

BÄHRE, Erik. Money and Violence: Financial self-help groups in a South African township. Leiden, Brill, 2007.

BOLTANSKI, Luc e THÉVENOT, Laurent. De la justification. Les economies de la grandeur. Paris, Gallimard, 1991. 
Borges, Antonádia. A cada passo: um estudo de redes e faccionalismo em um assentamento de atingidos por barragem. Dissertação de Mestrado, Antropologia, UFRGS, 1999.

. Tempo de Brasília: etnografando lugares-eventos da política. Relume Dumará, Rio de Janeiro, 2004a.

Depois de Bourdieu: abordagens sociológicas contemporâneas acerca das classes populares. Antropolítica (17), Niterói/Brasil, UFF, 2004b, pp.191-212.

. O emprego na política e suas implicações teóricas para uma antropologia da política. Anuário Antropológico, Brasília, Universidade de Brasília, 2005, pp.91-125.

. Anthropology and Social Experts: Agency, Creativity and the refusal to established Categories. Occasional Paper New Series, 1/2009, New Delhi, Department of Sociology, Delhi School of Economics, Delhi University, 2009a.

. Explorando a noção de etnografia popular: comparações e transformações a partir dos casos das cidades-satélites brasileiras $e$ das townships sul-africanas. Cuadernos de Antropología Social (29), Buenos Aires, Argentina, 2009b, pp.23-42.

. Women, Political Agency and the Creation of a Public Domain. Comunicação apresentada na Gender Justice and Body Politics Conference, Environmental and Geographical Science Building (EGS), University of Cape Town. 2009c. mimeo.

. Antropologia em Segredo: considerações tardias sobre um estudo etnográfico em um reassentamento de atingidos por barragem. In: CHAGAS, Miriam e Müller, Cinthia. (eds.) Dinâmicas de Cidadania: abordagens etnográficas sobre a diversidade. Porto Alegre, Edufrgs, 2010a, pp.165-195.

- Uma propriedade, diversas propriedades: etnografia, comparação e a distribuição de benefícios públicos no Brasil e na África do Sul. In: SIGAUD, Lygia et al. (orgs.). Brasil em Perspectiva. Rio de Janeiro, 7 Letras, 2010b.

BouRdiEU, Pierre. Célibat et condition paysanne. Études Rurales (5/6), 1962, pp.32-135. 
Reflexões etnográficas a partir do Brasil e da África do Sul

. La maison kabyle ou le monde renversé. In: Pouillon, Jean e MARANDA, Pierre. (eds.) Échanges et communications: mélanges offerts à Claude Lévi-Strauss.Paris, Mouton, 1972, pp.739-758.

. Le bal des célibataires. Crise de la société paysanne en Béarn. Paris, Le Seuil, 2002.

CARSTEN, Janet e Hugh-JONES, Stephen. About the House: Lévi-Strauss and Beyond. Cambridge, Cambridge University Press, 1995.

CEJAS, Mónica. Memoria, Verdad, Nación y Ciudadanía: algunas reflexiones sobre la comisión de la verdad y la reconciliación en Sudáfrica. Liminar. Estudios Sociales y Humanísticos 5(1), 2007, pp.24-34.

DAS, Veena. Life and Words. Violence and the Descent into the Ordinary. Berkeley, University of California Press, 2006.

DAS, Veena e POOLE, Deborah. (eds.) Anthropology in the Margins of the State. Santa Fe, School of American Research Press, 2004.

DEBERT, Guita Grin e GREGORI, Maria Filomena. Violência e gênero: novas propostas, velhos dilemas. Revista Brasileira de Ciências Sociais 23(66), 2008, pp.165-185.

FABIAN, Johannes. Time and the Other. How anthropology makes its object. New York, Columbia University Press, 1983.

FERGUSON, James. The Anti-Politics Machine. "Development", Depoliticization and Bureaucratic Power in Lesotho. Minneapolis, University of Minnesota Press, 1994.

. Global Shadows. Africa in the neoliberal world order. Londres, Duke University Press, 2006.

. Formalities of Poverty: Thinking about Social Assistance in Neoliberal South Africa. African Studies Review 50(2), 2007, pp.71-86.

FERNANDES, Heliza Cristina Cavalcanti. O negócio é correr atrás: associações comunitárias e engajamentos políticos no Recanto das Emas. Dissertação de Graduação, Antropologia, Universidade de Brasília, 2009. 
GARFINKEL, Harold. Studies in Ethnomethodology. Englewood Cliffs, New Jersey, Prentice-Hall, 1967.

GASA, Nomboniso. (ed.) Women in South African History. Basus'iimbokodo, Bawel'imilambo. They remove boulders and cross rivers. Cape Town, HRSC, 2007.

HARAWAY, Donna. Situated Knowledges: The Science Question in Feminism and the Privilege of Partial Perspective. Feminist Studies 17(3), 1988, pp.575-599.

HARRISON, Philip, HuCHZERMEYER, Marie \& MAYEKISO, Mzwanele. (eds.) Confronting fragmentation: housing and urban development in a democratising society. Cape Town, University of Cape Town Press, 2003.

HART, Gillian. Disabling Globalization: Places of Power in Post-Apartheid South Africa. Berkeley, University of California Press, 2002.

HASSIM, Shireen. Women's Organizations and Democracy in South Africa: Contesting Authority. Durban, University of Kwazulu-Natal Press, 2006.

HERZFELD, Michael. The Body Impolitic. Artisans and Artifice in the Global Hierarchy of Value. Chicago, Chicago University Press, 2003.

Holston, James. A cidade modernista. Uma crítica de Brasília e sua utopia. São Paulo, Companhia das Letras, 1993.

HUCHZERMEYER, Marie. Unlawful Occupation: informal settlements and urban policy in South Africa and Brazil. Trenton/NJ, Africa World Press/The Red Sea Press, 2004.

JENKIS, Timothy. The Life of Property: House, Family and Inheritance in Béarn, South-West France. New York, Berghahn, 2010.

KROG, Antjie, Mrolweni, Nosisi e Ratele, Kopano. There was this goat. Investigating the Truth Commission Testimony of Notrose Nobomvu Konile. Durban, University of Kwazulu-Natal Press, 2009.

Latour, Bruno. Politiques de la nature. Comment faire entrer les sciences en démocratie? Paris, La Découverte, 1999.

LATOUR, Bruno. Une sociologie sans objet? Remarques sur l'interobjectivité. In: DEBARY, Octave e TURGEON, Laurier. (dir.) Objets 
Reflexões etnográficas a partir do Brasil e da África do Sul

\& Mémoires. Paris, Éditions de la Maison des Sciences de l'Homme/ Québec, Presses de l'Université Laval, 2007.

LAW, John e HASSARD, John. (orgs.) Actor Network Theory and After. Oxford, Blackwell, 1999.

LÉvi-STRAUSS, Claude. Histoire et ethnologie. Annales. Économies, Sociétés, Civilisations 38(6), 1983, pp.1217-1231.

MABIN, Alan. Comprehensive Segregation: The Origins of the Group Areas Act and its Planning Apparatuses. Journal of Southern African Studies 18 (2), 1992, pp.405-429.

NADER, Laura. Ethnography as theory. HAU: Journal of Ethnographic Theory 1 (1), 201, pp.211-219.

NDEBELE, Njabulo. The Cry of Winnie Mandela. Oxfordshire/OX, Ayebia Clarke, 2003.

. Democracy Compromised: Chiefs and the Politics of Land in South Africa. Cape Town, HSRC Press, 2006.

e HALL, Ruth. The Land Question in South Africa: The Challenge of Transformation and Redistribution. Cape Town, HRSC, 2007.

OldFIELD, Sophie e STOKKE, Kristian. Building Unity in Diversity: Social Movement Activism in the Western Cape Anti-Eviction Campaign. In: HABIB, A. et alii. (eds.) Globalisation, Marginalisation and New Social Movements. Durban, University of Kwazulu-Natal Press, 2006, pp.25-49.

OOmEn, Barbara. Chiefs in South Africa: Law, Power \& Culture in the Post-Apartheid Era. Hampshire, Palgrave Macmillan, 2005.

PEIRANO, Mariza. Etnografia não é método, 2012. mimeo.

POSEL, Deborah. Marriage at the Drop of a Hat: Housing and Partnership in South Africa's Urban African Townships, 1920s-1960s. History Workshop Journal 61 (1), 2006, pp.57-76.

PeIRCE, Charles S. The doctrine of chances. In Houser, N. e KLOESEL, C. (eds.), The essential Peirce volume 1. Bloomington, Indiana University Press,1992, pp.142-154. [1878]. 
PINTO, Ana Cândida Pena Vieira A palavra de Deus: performance e pentecostalismo no Recanto das Emas. Dissertação de Graduação, Antropologia, Universidade de Brasília, 2011.

Ross, Fiona. Bearing witness: women and the Truth and Reconciliation Commission in South Africa. London, Pluto, 2003.

SEMÁN, Pablo. Mas allá de la descripción, más acá del dualismo: efectos cruciales de un recorrido entre países, investigaciones y disciplinas. Estudios Sociologicos de El Colegio de México XXVIII (81), 2009, pp.1041-1059.

STENGERS, Isabelle. Au temps des catastrophes. Résister à la barbarie qui vient. Paris, La Découverte, 2009.

Strathern, Marilyn. The Gender of the Gift. Problems with Women and Problems with Society in Melanesia. Berkeley, University of California Press, 1988.

VALE, Maíra Cavalcanti. Transbordando antropologias. Dissertação de Graduação, Antropologia, Universidade de Brasília, 2009.

WoortmanN, Klaas. A etnologia (quase) esquecida de Bourdieu, ou o que fazer com heresias. Revista Brasileira de Ciências Sociais 19(56), 2004, pp.129-137. 